\title{
EFEITO DO FÓSFORO NO DESENVOLVIMENTO INICIAL DE MUDAS DE GOIABEIRA SERRANA
}

\author{
J.C. NACHTIGAL; R.A. KLUGE; P.A.L. ROSSAL; L.C. VAHL'; A. HOFFMANN \\ Departamento de Solos, FAEM/UFPEL, C.P. 354, CEP: 96010-900, Pelotas, RS.
}

RISUMO: Foi estudado o efeito da adubação fosfatada no desenvolvimento inicial de mudas de goiabeira serrana (Feljoa sellowiana Berg.) num experimento em vasos, com solo Podz6lico Vermelho Amarelo, apresentando 4 ppm de $\mathbf{P}$ extraivel pelo método de Mehlich. Os níveis de fósforo utilizados foram $0,50,100$ e $150 \mathrm{ppm}$ de $P$, aplicados antes da instalação do experimento, juntamente com $150 \mathrm{ppm}$ de $\mathrm{K}$. Em cobertura, foram aplicados $150 \mathrm{ppm}$ de $\mathrm{N}$, em três parcelas iguais aos 7, 27 e 47 dias após a repicagem das mudas. Plântulas oriundas de sementes de plantas nativas, com aproximadamente 30 dias, foram transplantadas para os vasos e cultivadas durante 89 dias. Houve efeito significativo do P sobre todas as variáveis analisadas. A altura das plantas mostrou um comportamento similar a curva clássica do crescimento, mas os incrementos obtidos a cada avaliação aumentaram com os níveis de $\mathbf{P}$. A matéria seca das raízes e da parte aérea, bem como as quantidades extraídas de $N, P$ e $K$ aumentaram linearmente com os níveis de $P$. $O$ teor de $P$ no tecido aumentou até 0 nível de $50 \mathrm{ppm}$ de $P$ aplicado, permanecendo estável nos níveis maiores, enquanto os de $N$ e $K$ diminuiram nos níveis acima de 50 ppm de $P$. Os resultados obtidos permitem verificar a elevada exigência de fósforo desta espécie no periodo inicial de crescimento.

Descritores: Feijoa, goiabeira serrana, adubação, fósforo.

\section{EFFECT OF PHOSPHORUS ON THE INITIAL DEVELOPMENT OF FEIJOA SEEDLINGS}

\begin{abstract}
The effect of phosphate fertilization on the initial development of feijoa (Feljoa sellowiana Berg.) seedlings was studied in a pot experiment with a Red Yellow Podzolic soil having $4 \mathrm{ppm}$ of extractable phosporous by the Mehlich method. Levels of phosphorous of $0,50,100$ and $150 \mathrm{ppm}$ together with $150 \mathrm{ppm}$ of $\mathrm{K}$ were applied as a basal dressing. In three equal portions $150 \mathrm{ppm}$ of $\mathrm{N}$ were applied at 7, 27 and 42 days after the transplant of the seedlings. Seedlings of native plants, with 30 days approximately, were transplanted to pots and cultivated during 89 days. There was a significant effect of phosphorous on all analised variables. Plant height showed the behaviour of the classic growth curve, but the increments obtained at each evaluation increased with the levels of P. Root dry matter, aerial parts, as well as the extracted quantities of $N, P$ and $K$ increased linearly with the $P$ levels. The concentration of $P$ in the tissue increased up to the level of $50 \mathrm{ppm}$, remaining stable for the higher $P$ levels, those of $\mathrm{N}$ and $\mathrm{P}$ decreased for the levels above $50 \mathrm{ppm}$ of $\mathrm{P}$. Results obtained permit to verify the high requirement of this species in relation to phosphorous, in the initial growth period.
\end{abstract}

Key woris: Feijoa, fertilization, phosphorus

\section{INTRODUÇÃO}

A goiabeira serrana, também conhecida como goiabeira do mato ou feijoa é uma planta frutífera silvestre de porte arbustivo, pertencente à familia Myrtaceae. Encontrada em estado nativo em regiōes serranas do Rio Grande do Sul, Santa Catarina e Paraná, bem como em regióes do norte do Uruguai e Argentina (MATTOS, 1989). A partir de material proveniente destes centros de origem, foram obtidas seleções, que originaram

\footnotetext{
1 Bolsista do CNPq.
}

cultivares de expressão comercial em diversos países (MATTOS, 1988). O cultivo comercial da goiabeira serrana, como é conhecida internacionalmente, $\hat{\epsilon}$ praticado principalmente na Nova Zelândia, Azerbaijão e Israel. $O$ fruto possui poucas calorias e elevadas quantidades de sais minerais e vitamina $C$, o que o torna bastante valorizado para comercialização (SALUNKHE, 1976).

Recentemente, iniciaram-se alguns trabalhos de pesquisa visando a seleção de material 
nativo, técnicas de produção e tratos cuiturais, motivados pelo sucesso alcançado no cultivo desta espécie em diversos países (FRANCO, 1989; RASEIRA \& RASEIRA, 1989; FEIJOA, 1990).

A goiabeira serrana adapta-se bem a uma grande variedade de solos, desde arenosos até argilosos, devendo-se evitar aqueles que apresentam problemas de drenagem. Terrenos arenosos induzem preocupação constante com a irrigação e com o suprimento de matéria orgânica (FUNDACIÓN CHILE, 1990).

As práticas de adubação, visto não existirem normas para interpretação de análise de solo ou foliar, são geralmente baseadas em informações empíricas. ANDERSEN \& ANDERSEN (1988) recomendam aplicar 5 a $10 \mathrm{~kg}$ de esterco curtido por planta, acrescentando-se cerca de $200 \mathrm{~g}$ por ano de vida da planta da mistura composta de sulfato de amônio, superfosfato triplo e cloreto de potássio (50:50:20), caso as reservas do solo estiverem baixas. Recomendam ainda o preparo do solo para o plantio de mudas utilizando-se $10 \mathrm{~kg}$ de esterco curtido e $100 \mathrm{~g}$ de superfosfato triplo por planta. De um modo geral, a goiabeira serrana exige um alto suprimento de matéria orgânica, bem como uma atenção especial ao fósforo. Teores excessivos de nitrogênio induzem à formação de brotações laterais na base da planta e de ramos ladrões, prejudicando a frutificação (CACIOPPO, 1988).

DAL BÓ \& DUCROQUET (1992) verificaram que a correção do solo e a adubação fosfatada proporcionaram um aumento altamente significativo no crescimento inicial desta espécie. Esses autores recomendam a correção do solo para pH 6,0 e adubação fosfatada pré-plantio semelhante as outras espécies frutíferas de clima temperado. Estudos sobre o efeito de nutrientes nessa cultura podem ser baseados, por analogia, em resultados obtidos para outras mirtáceas cultivadas comercialmente, tais como a goiabeira (Psidium guajava) e o eucalipto (Eucalyptus spp.). Entretanto, mesmo para essas espécies, as informações são escassas, especialmente no que se refere à adubação na fase de desenvolvimento das mudas.

Segundo MARTINEZ JR. \& PEREIRA (1986), a goiabeira (Psidium guajava) apresenta respostas positivas à adubação nitrogenada no que diz respeito ao aumento da produtividade, enquanto que a resposta à adição de fósforo é positiva apenas em doses menores $(150 \mathrm{~g} /$ planta $\mathrm{P}_{2} \mathrm{O}_{5}$ ). Citam ainda que a resposta em produtividade e peso médio dos frutos em relação à adubação nitrogenada foi menos evidente em doses maiores de adubação. BRANDI et al. (1977), trabalhando com mudas de Eucalyptus citriodora, avaliaram o efeito de doses de nitrogênio, fósforo e potássio. Nas condições desse experimento, o fósforo foi o elemento mais eficiente parà a produção de mudas, sendo que bons resultados podem ser obtidos somente com a aplicação desse elemento, sendo a resposta ao nitrogênio e potássio menos marcante. HAAG (1983) cita efeito linear do nitrogênio sobre o crescimento de mudas de Eucalyptus camaldulensis quando em presença de fósforo, enquanto que a aplicação de fósforo não produziu resposta significativa sobre a altura das plantas.

Este experimento objetivou avaliar a resposta de mudas de goiabeira serrana a dosagens de fósforo.

\section{MATERIAL E MÉTODOS}

O trabalho foi conduzido em casa de vegetação pertencente ao CPACT/EMBRAPA, no período de 17 de setembro a 16 de dezembro de 1992.

Foi utilizado solo pertencente à unidade de mapeamento Camaquã, classificado como Podzólico Vermelho Amarelo (BRASIL, 1973). Os resultados da análise química do solo são apresentados na TABELA 1 . O solo foi coletado da camada arável $(0-30 \mathrm{~cm})$, no Centro Agropecuário da Palma (UFPEL), município do Capão do Leão, sendo peneirado úmido em peneira de $8,0 \mathrm{~mm}$ e então acondicionado em baldes plásticos com capacidade para 10 litros, colocando-se $7,8 \mathrm{~kg}$ de solo por balde. Foram utilizados quatro níveis de adubação fosfatada $(0,50,100$ e $150 \mathrm{ppm}$ de fósforo), na forma de superfosfato triplo. A aplicação do fertilizante fosfatado foi feita antes da instalação do experimento com $150 \mathrm{ppm}$ de potássio na forma de cloreto de potássio. Para todos os tratamentos foram aplicados $150 \mathrm{ppm} \mathrm{de}$ nitrogênio, na forma de uréia em solução aquosa, divididos em três parcelas iguais, com intervalos de 20 dias. Foi adotado o delineamento experimental inteiramente casualizado, com quatro repetições e 5 plantas por vaso.

As mudas utilizadas foram obtidas a partir de sementes de frutos oriundos do município de Vacaria,RS, semeadas no mês de julho de 1992. As mudas foram produzidas em tubetes plásticos com terra de mato peneirada. 
TABELA 1- Características químicas do solo utilizado no experimento.

\begin{tabular}{|c|c|c|c|c|c|c|c|}
\hline $\mathrm{pH}_{4 \mathrm{HEO}}$ & $\mathbf{p H}_{\text {SMP }}$ & M.O & $\mathbf{P}$ & $\mathbf{K}$ & $\mathrm{Na}$ & Al & $\mathrm{Ca}+\mathrm{Mg}$ \\
\hline & & (\%) & \multicolumn{3}{|c|}{-..- (ppm) -..- } & \multicolumn{2}{|c|}{$(\mathrm{me} / 100 \mathrm{ml})$} \\
\hline 5,2 & 6,0 & 3,26 & 4,0 & 83 & 14 & 0,5 & 3,3 \\
\hline
\end{tabular}

As mudas foram repicadas com aproximadamente 30 dias de idade, apresentando $1,0 \mathrm{~cm}$ de altura, a partir do nível do solo. Inicialmente, em cada balde foram colocadas 8 mudas, uniformemente distribuídas e, após ter-se verificado o pegamento, deixou-se apenas 5 mudas por vaso. O solo foi mantido com umidade correspondente à capacidade de campo (17\%), utilizando-se água destilada.

Durante o período de condução do experimento, foi realizada a avaliação de altura de plantas a cada 7 dias. Aos 89 dias após a repicagem foram avaliados os seguintes parâmetros:

a) peso da matéria seca das raízes, caule e folhas, determinado após secagem em estufa a $60^{\circ} \mathrm{C}$;

b) teores de nitrogênio, fósforo e potássio no tecido, sendo os métodos de digestão e análise descritos por TEDESCO (1985).

\section{RESULTADOS E DISCUSSÃO}

Houve efeito linear dos níveis de fósforo na produção de matéria seca da parte aérea e das raízes (Figura 1). Tal efeito foi insignificante nos primeiros dias após a repicagem, mas aumentou com a idade das plântulas, principalmente a partir dos 61 dias, como mostram os dados de altura da parte aérea (Figura 2).

A relação linear entre a matéria seca produzida e os níveis de $\mathrm{P}$ aplicados, mostra que não foi alcançado o máximo crescimento das plantas, mesmo com a aplicação de $150 \mathrm{mg} \mathrm{P} / \mathrm{Kg}$ de solo, isto é, não foi alcançada a correção plena da disponibilidade de $P$ para que as plantas alcançassem o máximo crescimento. Nesse mesmo solo, e com teores iniciais de $P$ semelhantes, a cultura do trigo alcançou o rendimento máximo com $120 \mathrm{Kg} \mathrm{P} \mathrm{O}_{2} / \mathrm{ha}$, em experimento de campo (PATELLA, 1980), o que equivale à aplicação de $26 \mathrm{ppm}$ de P. Num planossolo, que ocorre em áreas adjacentes ao Podzólico Vermelho Amarelo usado no presente trabalho, com características químicas e mineralógicas muito semelhantes às deste e com apenas 1,9 ppm de P, VAHL et al. (1982) obtiveram o máximo rendimento de milho com a aplicação de $120 \mathrm{ppm}$ de $P$, em casa de vegetação, usando vasos com o mesmo volume de solo deste experimento. As produções de matéria seca de milho por vaso, obtidas naquele trabalho, foram semelhantes às da goiabeira serrana obtidas no presente experimento, embora o milho tenha sido cultivado durante 36 dias e a goiabeira serrana durante 89 dias, após a repicagem. Isto é, embora a goiabeira serrana tenha mostrado um crescimento (acúmulo de matéria seca) cerca de 2,5 vezes mais lento do que o milho, necessitou mais fósforo do que este.

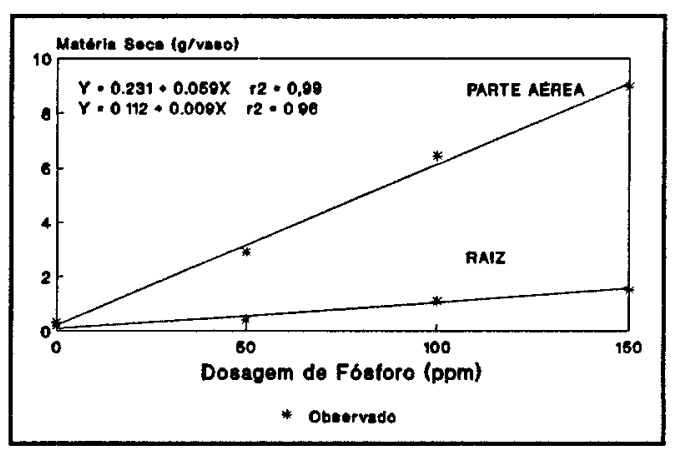

Figura 1 - Peso da matéria seca de 5 plantas de goiabeira serrana em quatro dosagens de fósforo.

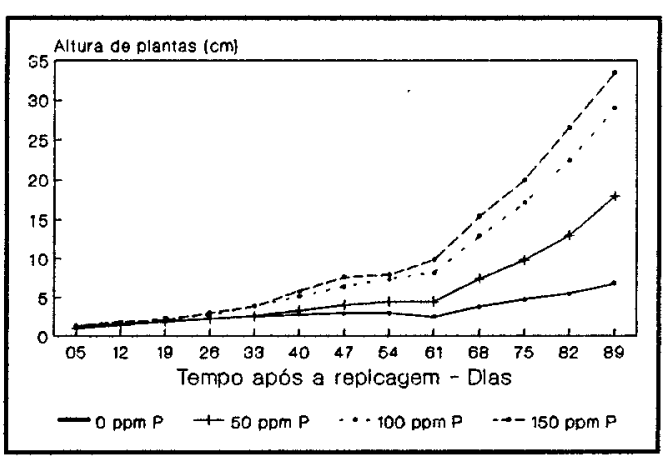

Figura 2 - Altura de plantas de goiabeira serrana cultivadas em vasos com solo Podźlico Vermelho Amarelo submetido a vários niveis de adubação fosfatada, em função do tempo após a repicagem. 
De acordo com os critérios adotados pela COMISSÃO DE FERTILIDADE DO SOLO (1989) para os solos do RS e SC, o teor inicial de P do solo usado no experimento, de classe textural 4 (11 a $25 \%$ de argila), enquadra-se como muito baixo. Esta faixa, segundo aqueles critérios, está relacionada à obtenção de pelo menos, $40 \%$ do rendimento máximo em culturas anuais, tais como cereais. $O$ rendimento relativo de matéria seca da parte aérea da goiabeira serrana neste experimento, no tratamento sem $P$, foi de apenas $2,2 \%$, considerando como $100 \%$ o rendimento obtido com 150 ppm de $P$ aplicado. $O$ valor real daquele rendimento relativo deve ser ainda menor, pois com 150 ppm não foi alcançada a produção máxima.

Tais comparações revelam a alta exigência de $P$ pela goiabeira serrana, ao contrário do que se esperaria, em se tratando de uma espécie nativa oriunda de região cujos solos são ácidos e extremamente pobres em P (DAL Bó \& DUCROQUET, 1992). Isto contraria a hipótese de que plantas desenvolvidas geneticamente em solos com baixa disponibilidade de um elemento, possuem alta capacidade de absorção e/ou alta eficiência de uso do mesmo (CLARKSON, 1985), o que conferiria baixa capacidade de resposta da planta à aplicação do elemento.

Os teores de $\mathbf{P}$ no tecido da parte aérea variaram de 0,18 a $0,26 \%$, mas aumentaram apenas do nível zero até o nível de $50 \mathrm{ppm}$ de $P$, mantendo-se estáveis nos níveis maiores de $P$ aplicado (TABELA 2). Os teores de $\mathrm{N}$ variaram de 1,55 a $2,12 \%$ e mostraram um comportamento diferente do $\mathbf{P}$, pois diminuiram com níveis de $\mathbf{P}$ acima de $50 \mathrm{ppm}$. Os teores de $\mathrm{K}$ no tecido mostram resposta aos niveis de $P$ semelhante ao $N$ (TABELA 2), O efeito do $\mathrm{P}$ nos teores de $\mathrm{N}$ e $\mathrm{K}$ no tecido pode ser atribuído à diluição do $\mathrm{N}$ e K em conseqüência do aumento de produção de MS promovido pela aplicação do $\mathrm{P}$.

o comportamento do $P$ no tecido, entretanto, é difícil de se explicar. A estabilização destes teores a partir de $50 \mathrm{ppm}$ de $P$ aplicado, poderia indicar que valores na faixa de $0,25-0,26 \%$ sejam suficientes para manter as plantas de goiabeira serrana bem nutridas em $P$. Se isto fosse verdadeiro, as plantas submetidas a $50 \mathrm{ppm}$ de $P$ já estariam com $P$ suficiente e não deveria ser observada uma resposta positiva à aplicação de níveis maiores de $P$, ao contrário do que foi observado. Por outro lado, o baixo teor de $P$ no tecido das plantas desenvolvidas no nível zero de $P$ aplicado $(0,18 \%)$, poderia ser considerado como sendo resultante da diluição máxima do $P$ absorvido. As plantas cresceram o máximo possível permitido pela quantidade de $P$ disponível no solo, mas neste caso, os teores nos níveis de 50 e 100 ppm deveriam ser menores do que os encontrados, porque estes níveis não foram suficientes para alcançar o máximo crescimento das plantas.

TABELA 2 - Teores de nitrogênio, fósforo e potássio no tecido da parte aérea de plantas de feijoa com 89 dias, cultivadas num solo Podzólico Vermelho Amarelo submetido a 4 níveis de fósforo, em casa de vegetação.

\begin{tabular}{lccc}
\hline $\begin{array}{l}\text { Niveis de } \\
\text { fósforo }\end{array}$ & \multicolumn{2}{c}{ Teores de nutrientes } \\
\cline { 2 - 4 } & $\mathrm{N}$ & $\mathrm{P}$ & $\mathrm{K}$ \\
\hline & & $(\%)$ & \\
\hline 0 & $1,92 \mathrm{~b}$ & $0,18 \mathrm{~b}$ & $1,73 \mathrm{~b}$ \\
50 & $2,12 \mathrm{a}$ & $0,26 \mathrm{a}$ & $2,22 \mathrm{a}$ \\
100 & $1,79 \mathrm{~b}$ & $0,26 \mathrm{a}$ & $2,08 \mathrm{ab}$ \\
\hline 150 & $1,55 \mathrm{c}$ & $0,25 \mathrm{a}$ & $2,05 \mathrm{ab}$
\end{tabular}

Médias seguidas de letras diferentes dentro da mesma coluna, diferem entre si, pelo teste de Duncan, ao nível de $5 \%$ de probabilidade.

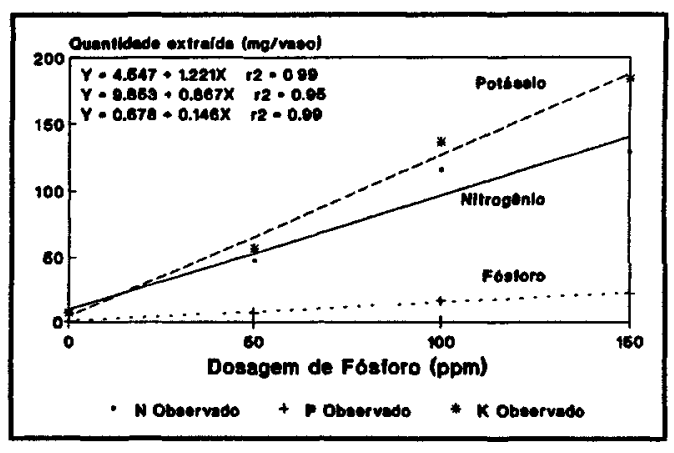

Figura 3 - Quantidade extraída de nitrogênio, fósforo e potássio pela parte aérea de 5 plantas de goiabeira serrana, em diferentes dosagens de fósforo. 
As quantidades de $N, P$ e $K$ acumulados na parte aérea (TABELA 2), obtidos pelo produto da matéria seca produzida pelos respectivos teores de cada elemento no tecido, relacionaram-se linearmente com os níveis de $\mathbf{P}$ aplicados (Figura 3), em consequiência da relação linear entre níveis de $P$ e a produção de matéria seca, efeito que sobrepujou a influência dos níveis de $P$ sobre os teores de cada elemento nas plantas.

\section{CONCLUSÃO}

A goiabeira serrana, embora seja uma espécie oriunda de regiões em que predominam solos ácidos e com disponibilidade de $\mathrm{P}$ muito baixa, é muito exigente neste elemento, pelo menos na fase inicial de crescimento.

\section{REFERÊNCIAS BIBLIOGRÁFICAS}

ANDERSEN, O.; ANDERSEN, V.U. As frutas silvestres brasileiras. Rio de Janeiro: Globo, 1988. 203p.

BRANDI, R.M.; CANDIDO, J.F.; BRAGA, J.M.; BARROS, N.F. Efeito da adubação NPK no desenvolvimento inicial de mudas de Eucalyptus citriodora Hook. Revista Ceres, Viçosa, v.24, n.134, p.405-411, 1977.

BRASIL. Ministério da Agricultura. Levantamento de Reconhecimento dos Solos do Estado do Rio Grande do Sul. Recife: Departamento Nacional de Pesquisa Agropecuária/Divisão de Pesquisa Pedológica, 1973. 431p. (Boletim Técnico, 30).

CACIOPPO, O. E dopo l'actinidia ecco la feijoa. Informatore Agrario, Verona, v.41, n.2, p.56-58, 1985.

CACIOPPO, O. La feijoa. Madrid: Mundi-Prensa, 1988, 85 p.

CLARKSON, D.T. Factors affecting mineral nutrient acquisition by plants. Annual Review of Plant Physiology, Palo Alto, v.36, p.77-115, 1985.

COMISSÃO DE FERTILIDADE DO SOLO - RS/SC. Recomendaçōes de adubação e calagem para os estados do Rio Grande do Sul e Santa Catarina. 2.ed. Passo Fundo: SBCS-Núcleo Regional Sul/ EMBRAPA-CNPT, 1989. 128 p.
DAL BÓ, M.A.; DUCROQUET, J-P. H.J. Efeito do pH e teor de $P$ no solo sobre o crescimento e absorção de nutrientes pela goiabeira serrana (Feijoa sellowiana). Revista Brasileira de Fruticultura, Cruz das Almas, v.14, n.2, p.109-114, 1992.

FEUOA: caindo de tāo madura. Alegre, n. 503, p.35-37, 1990

A Granja, Porto

FRANCO, H. Estas frutas ainda trarão divisas para SC. Agropecuária Catarinense, Florianópolis, v.2, n.2, p.47-51, 1989.

FUNDACIÓN CHILE. Cultivo e comercialización de feijoa. Informativo Agroeconomico, v.7, n.3, p.9-15, 1990.

HAAG, H.P. (Coord.) Nutrição mineral de Eucalyptus, Pinus, Araucaria e Gmelina no Brasil. Campinas: Fundaçāo Cargill, 1983, 101p.

MARTINEZ JR, M.; PEREIRA, F.M. Respostas da goiabeira a diferentes quantidades de $N, P$ e $K$. In: CONGRESSO BRASILEIRO DE FRUTICULTURA, 8., 1986, Brasilia. Anais... Brasília: EMBRAPA-DDT/ CNPq, 1986. p.293-296.

MATTOS, J.R. Goiabeira serrana. Porto Alegre: CEUE. 1988. 109p. (Fruteiras Nativas do Brasil, 2).

MATTOS, J.R. Myrtaceae do Rio Grande do Sul. Porto Alegre: CEUE, 1989. 721p.

PATELLA, J.F. Influência de quinze anos de adubação NPK sobre o rendimento do trigo e algumas propriedades químicas do solo. Revista Brasileira de Ciência do Solo, Campinas, v.4, n.1, p.31-35, 1980.

RASEIRA, A.; RASEIRA, M.C.B. Fruteiras nativas de clima temperado. HortiSul, Pelotas, v.1, n.2, p.47-51, 1989.

SALUNKHE, D. Storage processing and nutritional quality of fruits and vegetables. 2.ed. Cleveland: CRC Press, 1990. 2v.

TEDESCO, M.J. Análises de solo, plantas e outros materiais. Porto Alegre: UFRGS/ Faculdade de Agronomia, 1985. 188p.

VAHL, L.C.; TURATTI, A.L.; FISHER, J. Disponibilidade do fósforo aplicado ao solo após o cultivo do arroz irrigado por alagamento. Agros, Pelotas, v.17, n.3/4, p.47-55, 1982.

Enviado para publicação em $\mathbf{1 3 . 1 2 . 9 3}$

Aceito para publicação em 25.05 .94 